\title{
EVOLUÇÃO SEDIMENTAR E TECTÔNICA DA BACIA METASSEDIMENTAR DO RIO PARDO: UMA SÍNTESE
}

\author{
AUGUSTO J. PEDREIRA
}

\begin{abstract}
SEDIMENTARY AND TECTONIC EVOLUTION OF THE RIO PARDO METASEDIMENTARY BASIN: A SYNTHESIS The Rio Pardo Metasedimentary Basin $\left(\approx 15^{\circ} 40^{\prime} \mathrm{S} / 39^{\circ} 20^{\prime} \mathrm{W}\right)$, is divided into two sub-basins. The northeastern sub-basin deposited on the southeastern edge of the Sao Francisco Craton, and the southwestern underwent folding during construction of the Ara?uai Fold Belt, of Brasiliano age. The Rio Pardo Group fills the basin and comprises, from base to top, of the Panelinha Formation, the Itaimbe Subgroup, and the Salobro Formation. The former is composed of conglomerates, breccias, arkoses and graywackes. The Itaimbé Subgroup contains the Camaca (pelites and carbonates), Água Preta (phyllites), Santa Maria Eterna (sandstones and conglomerates), and the Serra do Paraiso (limestones and dolomites) formations that are laterally gradational. The Salobro Formation, unconformably deposited on the Itaimbé Subgroup, consists of polymitic conglomerates, arkoses and graywackes. The main depositional phase of these sediments was during the compressional episode of the Neoproterozoic Brasiliano Cycle. A northeast-southwest gravimetric profile along the basin shows a flexure of the basement north of the Pardo River, generating a foredeep containing the Salobro Formation. After their deposition, the sediments were subjected to three deformational episodes: the first and the second consist of coaxial folding and thrusts with northeast directed tectonic transport; in the third episode, the tectonic transport is from west to east. The main mineral resources presently exploited in the basin are the Serra do Paraiso Formation carbonates and, occasionally, diamonds of the Salobro Formation. The Rio Pardo Metasedimentary Basin evolved from an intracontinental rift system filled by alluvial fans and fluvial systems of the Panelinha Formation, unconformably overlain by the Itaimbé" Subgroup sediments. In this subgroup, the Camaca, Serra do Paraiso and Santa Maria Eterna formations respectively represent the deposition in muddy and carbonatic tidal flats, and beaches, and the Agua Preta Formation by turbidites of the basin's deeper parts. The Itaimbe' Subgroup sediments were involved in the Araguaf belt folding, with subsequent uplift and erosion, and deposited as the Salobro Formation into the foredeep formed by the crustal flexure north of the Pardo River in a foreland basin setting.
\end{abstract}

Keywords: Proterozoic, Rio Pardo Group, stratigraphy, sedimentology, tectonics

RESUMO A Bacia Metassedimentar do Rio Pardo ( $\left.\approx 15^{\circ} 40^{\prime} \mathrm{S} / 39^{\circ} 20^{\prime} \mathrm{W}\right)$, divide-se em duas sub-bacias. A de nordeste foi depositada sobre a borda sudeste do Cráton do São Francisco e a sudoeste foi envolvida no dobramento da Faixa Aracuaí, de idade brasiliana. O grupo Rio Pardo, que a preenche, compreende, da base para o topo, a formação Panelinha, o Subgrupo Itaimbé e a Formação Salobro. A primeira é composta por conglomerados, brechas, arcóseos e grauvacas; o Subgrupo Itaimbé consiste nas formações Camacã (pelitos e carbonatos), Água Preta (filitos), Santa Maria Eterna (arenitos e conglomerados) e Serra do Paraíso (calcários e dolomitos), que transicionam lateralmente entre si. A Formação Salobro, depositada discordantemente sobre o Subgrupo Itaimbé, é composta por conglomerados polimíticos, arcóseos e grauvacas. Os sedimentos tiveram sua fase principal de deposicão no Neoproterozóico, durante o episódio compressivo do Ciclo Brasiliano. Um perfil gravimétrico de direção nordeste - sudoeste ao longo da bacia, mostra uma deflexão do embasamento a norte do rio Pardo, formando uma fossa, atualmente preenchida pela Formação Salobro. Após sua deposição, os sedimentos foram submetidos a três fases de deformação: a primeira e a segunda consistem em dobramentos coaxiais e empurrões com transporte tectônico para nordeste; na terceira, os empurrões têm transporte tectônico de oeste para leste. Os principais recursos minerais atualmente em exploração na bacia são os carbonatos da Formação Serra do Paraíso e, esporadicamente, diamantes da Formação Salobro. A Bacia Metassedimentar do Rio Pardo evoluiu de um sistema de riftes intracontinentais preenchidos por leques aluviais e sistemas fluviais da Formação Panelinha, superpostos discordantemente pelos sedimentos do Subgrupo Itaimbé. Neste subgrupo, as formações Camacã, Serra do Paraíso e Santa Maria Eterna representam respectivamente deposição ẹm planícies de maré lamosa e carbonática, e praia; a Formação Agua Preta depositou-se como turbiditos nas partes mais profundas da bacia. Os sedimentos do Subgrupo Itaimbé foram envolvidos nos dobramentos da Faixa Araçaí, soerguidos e erodidos, depositando-se na depressão formada pela flexura da crosta a norte do rio Pardo como a Formação Salobro, que é interpretada como o preenchimento de uma bacia de antepaís.

Palavras-chaves: Proterozóico, Grupo Rio Pardo, estratigrafia, sedimentologia, tectônica.

INTRODUÇÃO A Bacia Metassedimentar do Rio Pardo está situada na região sudeste do Estado da Bahia, entre as latitudes $15^{\circ} 20^{\prime}-16^{\circ} 00^{\prime}$ 'sul e longitudes $39^{\circ} 00^{\prime}$ e $39^{\circ} 45^{\prime}$ oeste. Na bacia afloram rochas sedimentares de baixo grau de metamorfismo, de idade meso (?) a neoproterozóica, depositadas sobre gnaisses, migmatitos e granulitos paleoproterozóicos a arqueanos, por sua vez intrudidos por granitos e diques básicos do Mesoproterozóico. Ela está dividida em duas sub-bacias, separadas pela Falha Rio Pardo-Agua Preta. Esta falha é inversa, com transporte tectônico para nordeste: a sub-bacia nordeste está depositada sobre o Cráton do São Francisco, estabilizado no Brasiliano, e a sub-bacia sudoeste está envolvida nos dobramentos associados à Faixa Araçuaí, de idade brasiliana (Fig. 1).

Este trabalho objetiva sintetizar os conhecimentos relativos à geologia da Bacia Metassedimentar do Rio Pardo, expondo os principais problemas geocronológicos e propondo um modelo deposicional integrado à geotectônica da Faixa Araçuaí. Este modelo está baseado na coleta de novos dados e modifica em parte interpretacõos estratigráficas anteriores (Pedreira et al. 1969, Pedreira 1979), reavaliando o modelo geossinclinal de Siqueira et al.(1978), dentro dos modernos conceitos de geotectônica.

ESTRATIGRAFIA O embasamento da Bacia Metassedimentar do Rio Pardo no domínio do Cráton do São Francisco consiste em granulitos quartzo feldspáticos, khondalitos, hiperstênio granulitos, enderbitos e granulitos básicos (Souto et al 1972), intrudidos por gabros e diques de diabásio datados por Cordani \& lyer (1976) entre 800 e 1.10OMa. No domínio da Faixa Araçuaí, no sul da bacia, as rochas compreendem gnaisses e migmatitos, com intercalações de anfibolitos, quartzitos, xistos e rochas calcissilicáticas (Mascarenhas cia/. 1979)

As rochas metassedimentares do Grupo Rio Pardo, da base para o topo, compreendem as formações Panelinha $(200 \mathrm{~m})$, Camacã (2000m), Água Preta (2300m), Santa Maria Eterna, Serra do Paraíso $(1000 \mathrm{~m})$ e Salobro $(5000 \mathrm{~m})$. As espessuras estão de acordo com Karmann et al (1989) e a da Formação Santa Maria Eterna não foi determinada.

Durante as etapas iniciais do mapeamento geológico da bacia (Pedreira et al. 1969), foi sugerido um empilhamento estratigráfico do tipo layer cake, para as formações da bacia: a Formaçãp Salobro estaria entre as formações Camacã e Água Preta, em contato gradativo com a primeira, embora a análise dos sedimentos das duas primeiras tenha sugerido condições tectônicas distintas em suas áreas-fonte (Souto et ai. 1912). A posição das formações Serra do Paraíso e Santa Maria Eterna também foi um assunto controverso: Pedreira et al.(1969) as colocaram no topo da sequência; Siqueira et al (1978) as posicionaram na base. Esta controvérsia foi resolvida por Karmann (1987), que demonstrou a existência de transição lateral entre as formaçõeș: de norte para sul, a Formação Camacã transiciona para a Formação Âgua Preta, e esta para a Formação Serra do Paraíso, que está depositada em parte sobre o embasamento. A presença de clastos de rocha carbonática na base da Formação Salobro (Conglomerado Lapão; Fig. 2) evidencia a posição superior da Formação Serra do Paraíso e a sua erosão precoce durante a deposição da Formação Salobro.

As formações Camacã, Água Preta, Serra do Paraíso e Santa Maria Eterna estão reunidas no Subgrupo Itaimbé sobre o qual depositou-se discordantemente a Formação Salobro. Os conglomerados desta formação, de acordo com Karmann (1987), contểm clastos cuja composição é semelhante à das formações subjacentes, inclusive do embasamento cristalino. A análise petrográfica de algumas lâminas delgadas dessa formação efetuada pelo petrógrafo Raymundo J. B. Fróes, da Companhia Baiana de Pesquisa Mineral-CBPM, indicou a presença de fragmentos de rochas das formações subjacentes à Formação Salobro, e do embasamento (granitos e gnaisses). 
Os sedimentos cenozóicos são representados pela Formação Barreiras, composta por areias, argilas, e camadas e lentes de cascalho, terraços formados por conglomerados inconsolidados (Formação PauBrasil) e aluviões recentes, arenosos e argilosos. A coluna estratigráfica da bacia é mostrada na figura 2 .

A interpretação dos ambientes deposicionais das rochas do Grupo Rio Pardo confirma as determinacões de carbono e oxigénio efetuadas por Costa Pinto (1977), que indicaram ambiente marinho e parcialmente cçntinental para a Formação Camacã, marinho para as formacões Âgua Preta e Serra do Paraíso e de água saloba para a Formacão Salobro. Uma constatação interessante dessa autora é a similaridade (isotópica) entre as lentes de carbonato da Formação Água Preta e a Formação Serra do Paraíso, confirmando a passagem lateral entre elas determinada por Karmann (1987).

GEOCRONOLOGIA As primeiras determinações de idade do Grupo Rio Pardo foram feitas por Cordani (1973) pelos métodos $\mathrm{Rb}-\mathrm{Sr}$ e K-Ar em rocha total e K-Ar em flogopita de filitos, ardósias e mármores das formacõos Agua Preta, Camacã e Serra do Paraíso, derivados da faixa de dobramento (Tabela 1). A isócrona de referência mencionada na tabela, com idade de 670Ma, é concordante com as datacõos K-Ar e corresponde à época de fechamento dos sistemas, em relação à difusão de argônio e redistribuição de estrôncio (Cordani \& lyer 1976). Os mesmos autores consideram que a razão inicial de 0,724 representa um intervalo de tempo de 100 a $200 \mathrm{~m}$. a. entre a deposição dos sedimentos e o mencionado fechamento, que corresponderia ao resfriamento regional da faixa dobrada. Neste caso, a deposição do Grupo Rio Pardo teria ocorrido no máximo há $670 \mathrm{Ma}$, no período Criogeniano.

Os mesmos dados foram tratados por Karmann (1987), que obteve uma idade isocrônica de 541, 4ะ78,3Ma. Adotando 1.100Ma como idade mínima de intrusão dos diques de diabásio sobre os quais está depositada a bacia, Karmann (1987) determinou sua deposição entre 1. 100 e $500 \mathrm{Ma}$, o que estenderia a idade máxima dos sedimentos para o período Esteniano (1200-1000Ma), no final do Mesoproterozóico.

Mascarenhas \& Garcia (1969) no Mapa Geocronológico da Bahia, colocaram o Grupo Rio Pardo entre 700 e $450 \mathrm{Ma}$, principal período de sedimentação do Neoproterozóico. O principal evento tectonomagmático compressivo do Ciclo Brasiliano é datado em $600 \pm 100 \mathrm{Ma}$ (Delgado et al 1994).

Desse modo, embora não exista consenso relativamente à idade máxima da sedimentação do Grupo Rio Pardo, os dados de Cordani \& lyer (1 976), Karmann (1987) e Mascarenhas \& Garcia (1989), indicam que a fase final da sua deposição seguramente se processou durante esse evento compressivo.

Recentemente, foram analisados na Australian National University, grãos de zircão em amostra do topo da Formação Salobro. As análises, efetuadas pelo método SHRIMP, forneceram idades aparentes $\left({ }^{207} \mathrm{~Pb}\right.$ ${ }^{206} \mathrm{~Pb}$ ) de $2.068 \pm 14$ e $2.103 \pm 18 \mathrm{Ma}$ (U. Cordani, com. escrita 1999), semelhantes às do embasamento cristalino a norte e sul da bacia.

TECTÔNICA Geofísica Objetivando relacionar os dados estruturais disponíveis para a Bacia Metassedimentar do Rio Pardo com o seu ambiente tectônico, foi feito um modelamento gravimétrico da bacia e do seu embasamento. O modelamento foi feito pelo geofísico Raymundo A. Dias Gomes, do Serviço Geológico do Brasil, utilizando o GRAVPOLY, software específico que emprega o algoritmo de Talwani (Talwani \& Heirtzler 1964). Foi modelado um perfil entre a cidade de Santa Luzia e o rio Jequitinhonha a sudoeste de Ventania, aproximadamente paralelo à seção estrutural da figura 1 , com direção azimutal $30^{\circ}$ e extensão de $125 \mathrm{~km}$; parte do perfil é mostrada na figura 3. Foram determinados os seguintes valores de densidade das rochas:
A

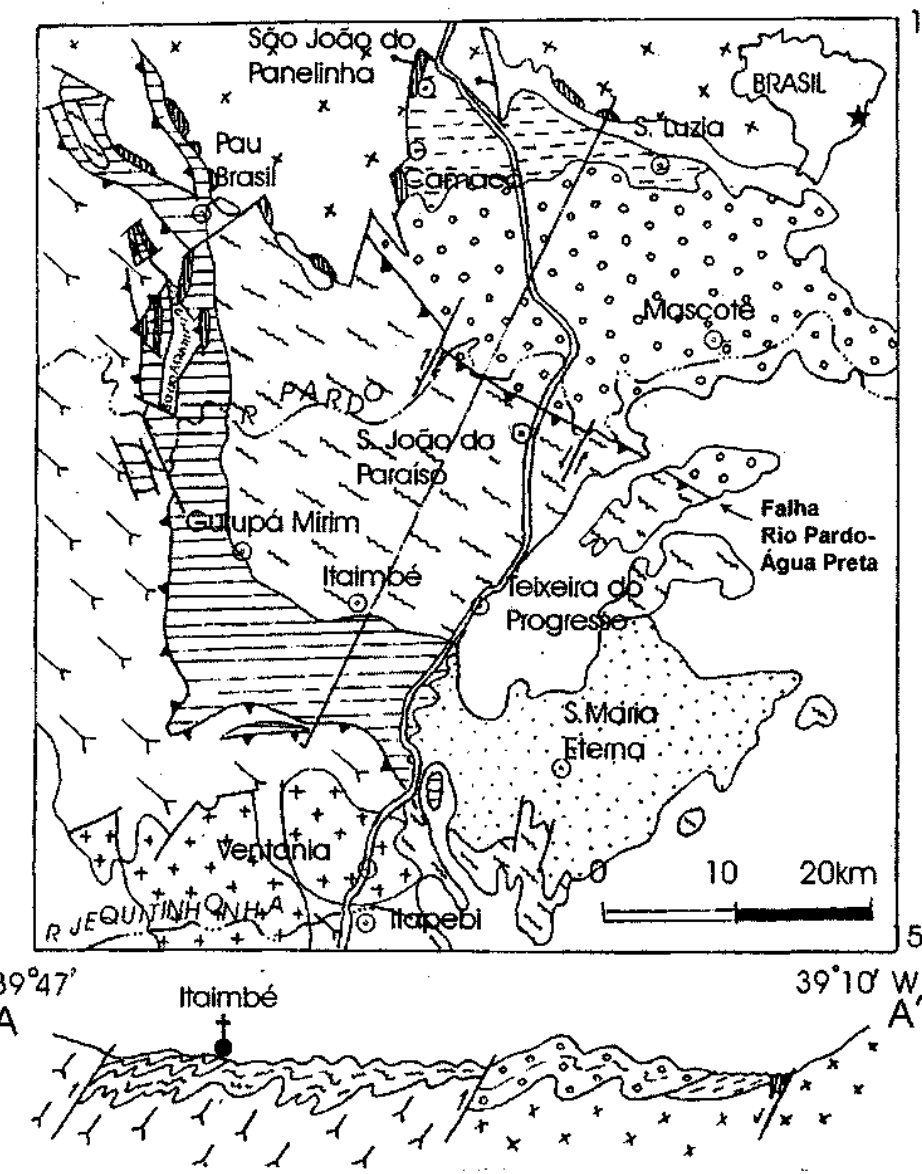

$15^{\circ} 20^{\prime}$

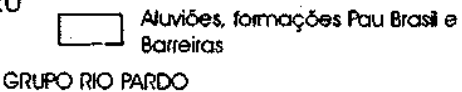

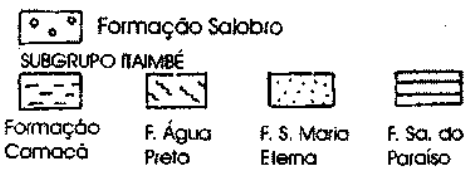

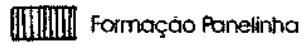

\section{EMPASAMENTO}

$\rightarrow$ Diques de diabásio

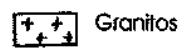

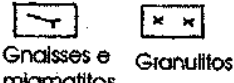

migmatitos

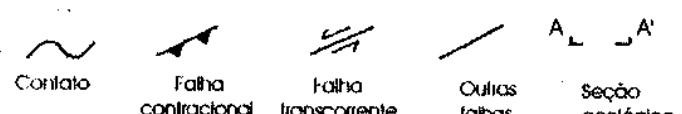

B

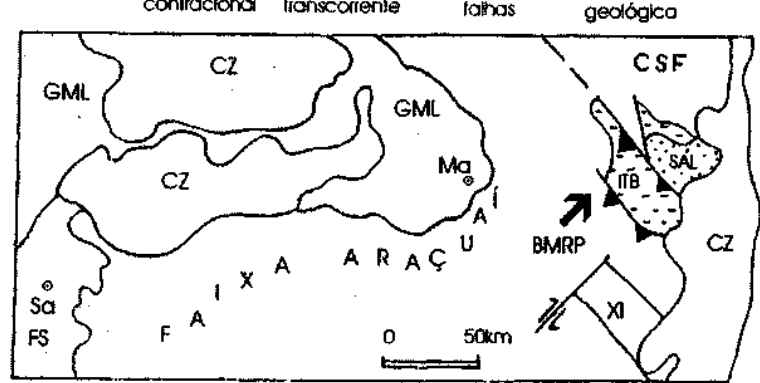

Figura l-A: Esboço geológico e seção estrutural esquemática da Bacia Metassedimentar do Rio Pardo (mapa geológico compilado de Pedreira 1996; seção baseada em Karmann 1987). B: Situação regional da Bacia Metassedimentar do Rio Pardo (modificada de Pedrosa-Soares 1996). Legenda: BMRP-Bacia Metassedimentar do Rio Pardo; CSF- Cráton do São Francisco; CZ- Coberturas cenozóicas; FS- Formação Salinas; GMI- Grupo Macaúbas Indiviso; ITB- Subgrupo Itaimbé; SAL-Formação Salobro; XI- Xistos de Itagimirim. Localidades: Ma-Maiquinique; Sa-Salinas. 
Regional $=2,78 \mathrm{~g} / \mathrm{cm}^{3}$

Rochas metassedimentares $=2,62 \mathrm{~g} / \mathrm{cm}^{3}$

Embasamento

"Nível" superior $(\mathrm{dcl})=2,77 \mathrm{~g} / \mathrm{cm}^{3}$

"Nível" inferior $(\mathrm{dc} 2)=2,79 \mathrm{~g} / \mathrm{cm}^{3}$

Granito $=2,7 \mathrm{~g} / \mathrm{cm}^{3}$
O perfil mostra os contrastes de densidade (diferença entre as densidades médias das rochas e as medidas no campo), e um gradiente lateral crescente para nordeste. Entre 42 e $55 \mathrm{~km}$ e 77 e $87 \mathrm{~km}$ da origem, existe um aumento acentuado do gradiente gravimétrico, caracterizando duas descontinuidades da crosta: as falhas do Rio Pardo-Água Preta e do Rio São Pedro. A modelagem entre 34 e 82 km da origem,

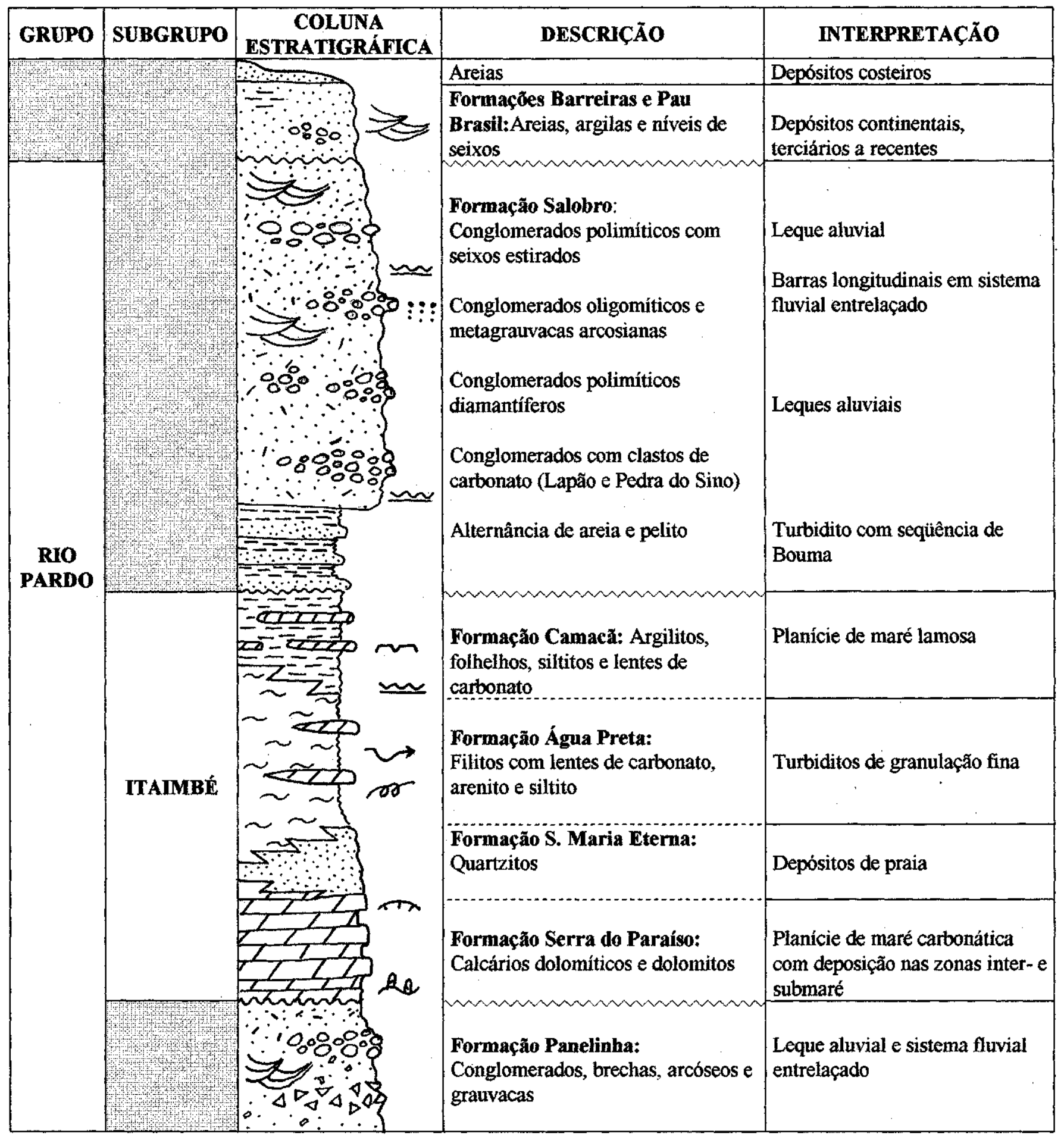

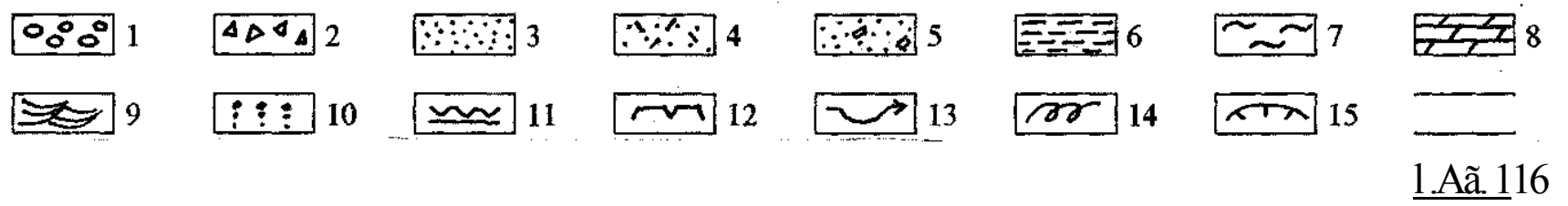

Figura 2 - Coluna estratigráfica da Bacia Metassedimentar do Rio Pardo (escala vertical arbitrária). Legenda: l-Conglomerado; 2-Brecha; 3-Arenito; 4-Grauvaca; 5-Arcóseo; 6-Pelitos em geral; 7-Filito; 8-Carbonatos; 9-Estratificação cruzada acanalada; 10-Granocrescência; 11-Marcas onduladas; 12-Fendas de ressecamento; 13-Marcas de sola;14-Estrat. convoluta; 15-Laminito algal; 16-Estromatólito colunar 
Tabela l - Determinações radiométrícas nos metassedimentos do Grupo Rio Pardo (mod. de Cordani \& lyer, 1976). Os asteriscos indicam isócronas de referência com $T=470 M a$ e $R I=0,724$ (RT= rocha total).

\begin{tabular}{|l|c|c|c|c|}
\hline \multicolumn{1}{|c|}{ Amostra } & Formação & Rocha & Método & Idade (Ma) \\
\hline BA-69-8 & Água Preta & Filito & Rb-Sr RT & $580^{*}$ \\
\hline CÃ-18 & Água Preta & Filito & Rb-Sr RT & $600^{*}$ \\
\hline & & & K-Ar RT & $470 \pm$ \\
\hline PB-33-27 & Água Preta & Filito & Rb-Sr RT & $670^{*}$ \\
\hline BA-69-13A & Camacã & Ardósia & Rb-Sr RT & $670^{*}$ \\
\hline CÃ-39 & Água Preta & Filito & K-Ar RT & $500 \pm 30$ \\
\hline & & & Rb-Sr RT & $640^{*}$ \\
\hline CB-CAL & S. do Paraíso & Mármore & K-Ar (flog.) & $530 \pm 50$ \\
\hline & & & & $495 \pm 35$ \\
\hline
\end{tabular}

sugere um espessamento da crosta, com urna depressão indicada pela interface dcl/dc2, a nordeste da Falha do Rio Pardo-A gua Preta.

Neste perfil podem se distinguir claramente os dois compartimentos em que se divide a bacia. A sua divisão em dois compartimentos estruturalmente distintos, foi determinada por Pedreira (1976), pela análise dos lineamentos representativos de fraturas em imagem de radar SLAR e fotos aéreas convencionais.

Geologia estrutural Em trabalho mais completo sobre a tectônica do Grupo Rio Pardo, Karmann (1987) analisou separadamente as estruturas dos dois compartimentos em que se divide a bacia. Essa análise detectou neles três fases de deformação, ocorridas após a deposição dos sedimentos, produzidas por esforços compressivos.

A primeira deformação, com transporte tectônico de sudoeste para nordeste, produziu dobras a nordeste do rio Pardo, com clivagem ardosiana nas rochas de granulação fina e clivagem espaçada nas de granulação grossa. As evidências desta deformação na Formação Panelinha são incipientes e nas formações Salobro e Camacã foram detectadas falhas contracionais, inclusive de baixo ângulo, com transporte tectônico para nordeste, associadas a dobras recumbentes. Segundo Karmann et al. (1989) a Falha Rio Pardo-Agua Preta é resultante dessa deformação, que provocou um encurtamento de $15 \%$ no pacote sedimentar. Próximo a esta falha, os seixos dos conglomerados do topo da Formação Salobro estão estirados $\left(25^{\circ} \rightarrow 280^{\circ}\right)$.

A segunda deformação, mais importante e superposta à primeira, pode ter sido uma reativação dela (Karmann 1987). Esta deformação está impressa principalmente a sul do rio Pardo e provocou um encurtamento de $35 \%$ a $40 \%$ do pacote sedimentar. Suas evidências começam a aparecer a sul do rio Pardo, com a formação de clivagens ardosiana e de fratura, bem como dobras abertas e fechadas com vergência para nordeste. Karmann (1987) sugere a possibilidade de um descolamento basal nessa fase, de modo que o conjunto litológico a sul do rio Pardo é subautóctone; a deformação seria causada pelas falhas inversas do embasamento.

A última deformação é evidenciada pela compressão da baciapara leste e está associada às falhas inversas das regiões das serras da Agua Branca e do Paraíso. A superposição das duas últimas deformações deu origem a figuras de interferência do Tipo 1 (domo e bacia), detectadas por Karmann (1987) na gruta de São Gotardo, situada em carbonatos da Formação Serra do Paraíso, entre as localidades de Itaimbé e Teixeira do Progresso.

Essas estruturas caracterizam os dois compartimentos determinados por Pedreira (1976), que foram recentemente denominados por Egydio-Silva et al. (1993) de Zona de Faixa Dobrada (o compartimento sudoeste, alóctone) e Zona Pericratônica (o compartimento nordeste, autóctone a subautóctone).

RECURSOS MINERAIS Os recursos minerais da bacia consistem em diamantes garimpados nos aluviões derivados dos conglomerados da Formação Salobro, ouro primário hospedado nos metassedimentos da Formação Água Preta, rochas carbonáticas da Formação Serra do Paraíso, areia silicosa de alta pureza originada da decomposição da Formação Santa Maria Eterna e conglomerados inconsolidados, tanto da Formação Pau Brasil, como os atribuídos à Formação Barreiras. Os diamantes têm sido garimpados desde o século passado e foram reavaliados em 1996. Ultimamente as rochas carbonáticas aflorantes na localidade de Toca da Onça, a sul de Itaimbé, estão sendo mineradas para a fabricação de corretivo de solo. Uma revisão sobre esses recursos recentemente foi publicada pela Companhia Baiana de Pesquisa Mineral-CBPM (Pedreira 1996).
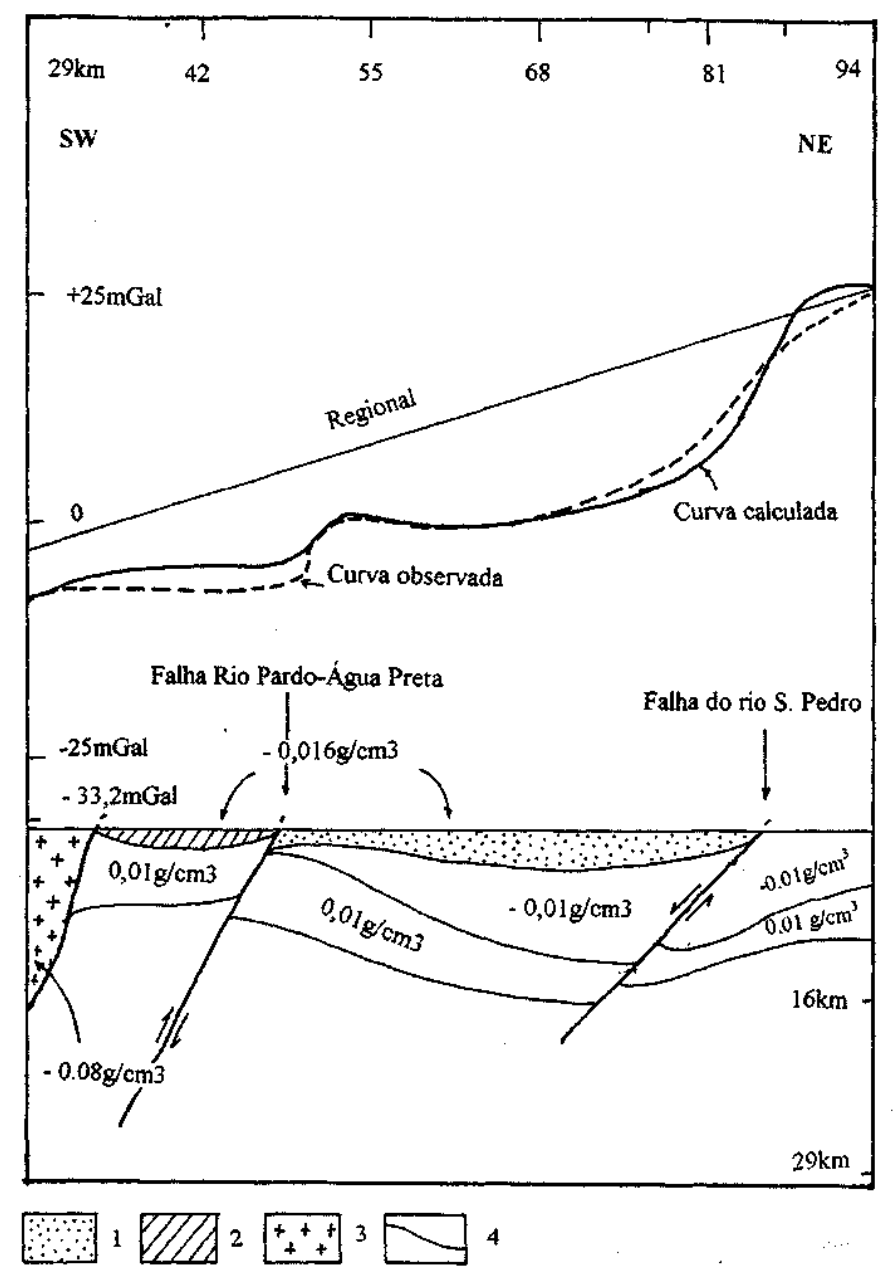

Figura 3 - Perfil gravimétrico da Bacia Metassedimentar do Rio Pardo. Legenda: l-Formações Salobro, Camacã e Panelinha; 2Subgrupo Itaimbé; 3-Granito; 4-Embasamento

DISCUSSÃO Não obstante as pequenas dimensões atuais da bacia (cerca de $3.600 \mathrm{~km}^{2}$ ), existem evidências»)de sua extensão prévia até pelo menos $60 \mathrm{~km}$ para noroeste, constantes de corpos carbonáticos encaixados em zonas de falha, e para leste, sob a plataforma continental (Pedreira 1979). O exame das características sedimentológicas e tectônicas da bacia sugerem que sua área atual seja apenas parte da original, paralela à faixa dobrada, trapeada e preservada da erosão em uma abertura pull-apart (B.B. de Brito Neves, com. pessoal). A evolução sedimentar e tectônica da bacia interpretada a partir dos dados expostos ao longo do texto está resumida na figura 4, que mostra evolução de um rifte intracontinental para uma bacia de antepaís.

Rifte intracontinental Os diques de diabásio precursores da separação continental (Fig. 4A) estão expostos no flanco norte da bacia e não a cortam, pertencendo a uma etapa pré-rifte. Os diques pertencem à mesma geração dos que afloram em Ilhéus e Olivença (Tanner de Oliveira \& Corrêa Gomes 1991). Os sistemas de leque aluvial e os arcóseos e grauvacas da Formação Panelinha (Fig. 2) são indicativos de deposição e soterramento rápidos, sugerindo sua origem em blocos elevados do embasamento (Fig. 4B).

A interpretação desta sequência como leques aluviais e rios entrelaçados, está de acordo com as fácies descritas por Vine (1998) para zonas de riftes precoces, que são caracterizadas por depósitos de leques, lacustres e fluviais; na Bacia Metassedimentar do Rio Pardo, estão presentes os primeiros e os últimos (Fig. 2).

Bacia remanescente No Subgrupo Itaimbé (Fig. 4C), a sedimentação das formações Camacã, Agua Preta, Serra do Paraíso e Santa Maria Eterna foi controlada pela variação da profundidade da lâmina d'água, de modo que as formações onde predominavam sistemas 
deposicionais de planície de maré lamosa, carbonática e litoral se distribuíam na periferia da bacia ou em zonas mais rasas, ao passo que os turbiditos depositaram-se na sua parte central e na atual borda sul. A morfologia da linha de costa, com saliências e reentrâncias, exerceu controle sobre a distribuição das fácies dentro desses sistemas e a localização dos sistemas fluviais na periferia da bacia controlou o afluxo de material terrígeno.

Os sedimentos do Subgrupo Itaimbé podem ser comparados com o preenchimento de uma bacia remanescente (remnant basin), definida por Ingersoll et al. (1995) como "uma bacia oceânica contracional que é flanqueada pelo menos por uma margem convergente, e cujo assoalho é coberto tipicamente por turbiditos derivados de zona(s) de sutura associada(s)". Nas partes proximais desses sedimentos pode existir exposição subaérea (Dominguez 1993). Os turbiditos, fluxos gravitacionais de massa (Souto et al, 1971 p.19) flysch calcário ou margoso correspondem à Formação Âgua Preta, enquanto as feições de exposição subaérea encontram-se nas demais formações do subgrupo (Karmann, 1987).

O Subgrupo Itaimbé pode ser correlacionado com as formações envolvidas na Faixa Araçuaí com base nas seguintes evidências: i) similaridade dos xistos da Formação Agua Preta que ocorrem ao longo da rodovia BR-101, com os biotita-granada-estaurolita xistos que afloram em Itagimirim, cerca de $16 \mathrm{~km}$ a sul de Itapebi (ver a Fig. 1 B), que foram atribuídos ao Grupo Macaúbas por Siqueira et al (1978); ii) presença, na Formação Salinas (Grupo Macaúbas), de litologias e estruturas sedimentares características de turbiditos, como marcas de sola e laminações convolutas (Pedrosa Soares 1996, e Formação Água Preta na figura 2). Esta correlação mostraria a dimensão aproximada da bacia remanescente (Fig. 1B).

Bacia de antepaís A Formação Salobro começa por turbiditos, seguidos por conglomerados de clastos de carbonato (conglomerados Lapão e Pedra do Sino; Fig. 2). Os demais conglomerados são polimíti$\cos$, com clastos de origem atribuída às formações subjacentes; no topo da formacão, os clastos dos conglomerados estão estirados, indicando transpressão ao longo da Falha Rio Pardo - Água Preta, com transporte tectônico para nordeste. As metagrauvacas arcosianas que compõem o restante da formação contêm fragmentos de carbonato, granito e gnaisse. Isto indica a proveniência dos sedimentos de áreas elevadas a sul da bacia (Fig. 4D), com denudação progressiva dos sedimentos carbonáticos para o embasamento e deposiç̃o em uma antefossa (Siqueira et al. 1978). Esta antefossa resultou do empilhamento de escamas de empurrão sobre o embasamento, o que provocou uma deflexão da crosta (Fig. 3), e dentro da qual depositou-se a Formação Salobro (Fig. 4E).

A sucessão de fácies da Formação Salobro (turbiditos -leques submarinos - sistemas fluviais; Karmann et al. 1989), é semelhante à mostrada por Einsele (1992) para o preenchimento de bacias de antepaís (marinho profundo -leque submarino - marinho raso - deltaico - fluvial).

CONCLUSÕES Não obstante a incipiente abordagem das pesquisas efetuadas até hoje na Bacia Metassedimentar do Rio Pardo, principalmente no que diz respeito à idade da sedimentação/diagênese das diversas formacões e à cronologia das deformacões, a partir dos dados expostos neste trabalho pode-se inferir que nela está registrado parcialmente um Ciclo de Wilson, compreendendo as etapas rifte, bacia remanescente e bacia de antepaís (Fig. 5).

A etapa rifte é representada, em primeiro lugar, pelos enxames de diques, e, em seguida, pela deposição de grauvacas, conglomerados e brechas da Formação Panelinha em riftes precursores da separação continental. Esses riftes se estendem para sul até pelo menos a região da serra da Agua Branca (Fig. 1), onde existem afloramentos da Formação Panelinha.

A bacia remanescente foi formada durante a separação dos blocos continentais (Cráton de São Francisco e o embasamento da Faixa Araçuaí), e está representada na Bacia Metassedimentar do Rio Pardo pelo Subgrupo Itaimbé. A deposição da Formação Agua Preta, que também esta preservada na atual borda sul da bacia (Fig. IA), sua correlação com os xistos de Itagimirim, e destes com o Grupo Macaúbas, sugerem a sua extensão para sudoeste, até a zona de subducção formada durante a convergência entre o Cráton do São Francisco e o embasamento da Faixa Araçuaí. O setor da bacia remanescente preservado na Bacia Metassedimentar do Rio Pardo é a sua parte proximal, não relacionada à zona de subducção.

A bacia de antepaís resultou da convergência e colisão entre o Cráton do São Francisco e o embasamento da Faixa Araçuá e consequente encurtamento da crosta que culminou na principal fase com-

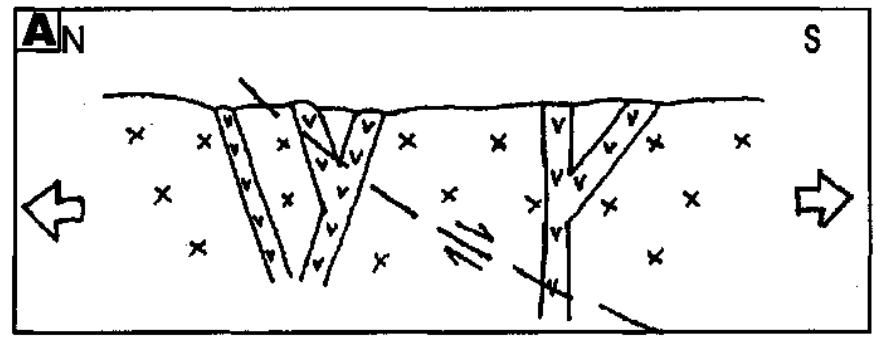

Intrusão de diques de diabásio precursores da separação continental.

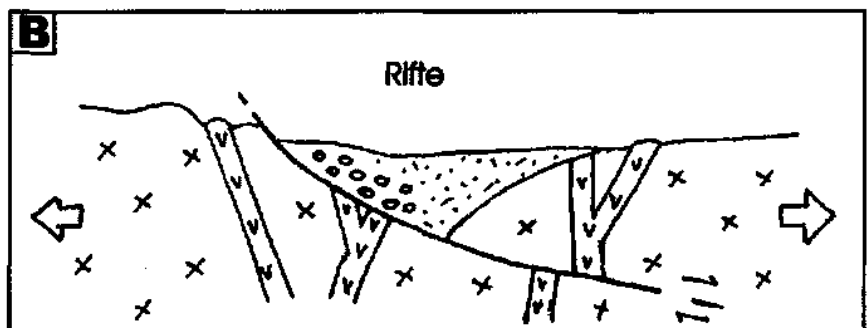

Deposição da Formação Panelinha em rifte intracontinental,como leques aluviais e sistemas fluviais entrelaçados e desenvolvimento de margem continental.

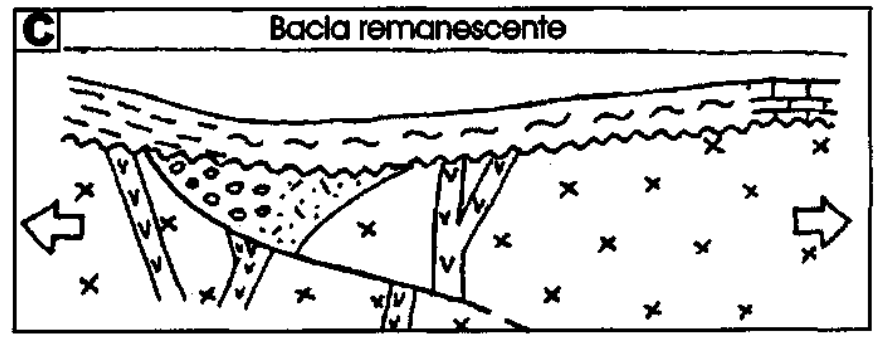

Deposição das formaçõesCamacã, Serra do Paraíso e Santa Maria Eterna nas margens da bacia, e da Formação Água Preta nas partes mais profundas da mesma.

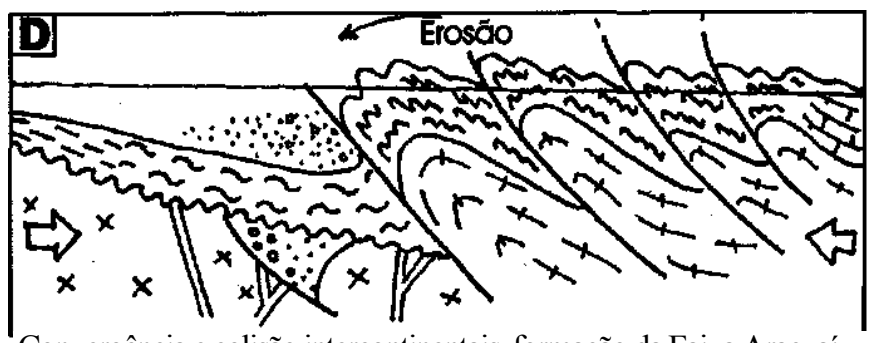

Convergência e colisão intercontinentais, formação da Faixa Araçuá, com envolvimento maior das formações depositadas na margem sul da bacia, erosão das formações meridionais e deposição da Formação Salobro.

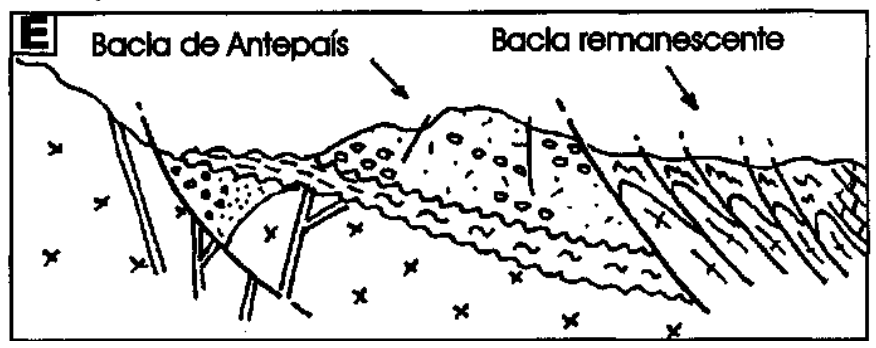

Situação atual: as formações Camacã, Água Preta, Serra do Paraíso e Santa Maria Eterna representam a bacia remanscente e a Formação Salobro preenche a bacia de antepaís.

Figura 4 - Principais etapas da evolução da Bacia Metassedimentar do Rio Pardo 
ESTRATIGRAFIA

INTERPRETAÇÃO

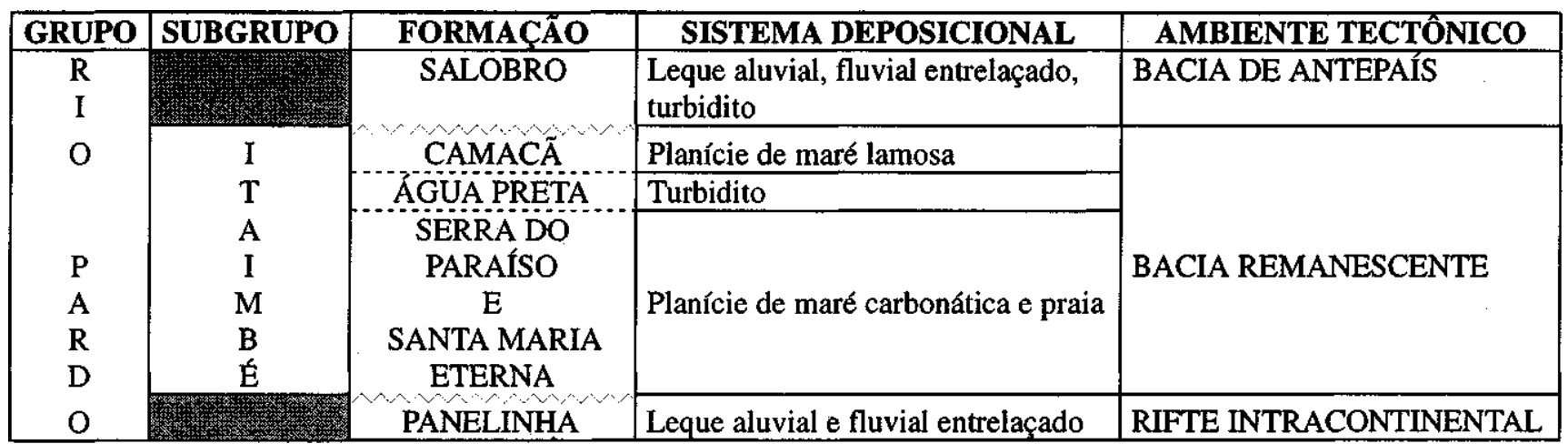

Fig. 5 - Estratigrofia, sistemas deposicionais e tectônica proterozóicos, da Bacia Metassedimentar do Rio Pardo.

pressiva do evento Brasiliano $(600 \pm 100 \mathrm{Ma})$. O empilhamento de escamas de empurrão aumentou a carga sobre a crosta, gerando por subsidência flexural uma depressão na borda do cráton, a qual foi preenchida pela Formação Salobro, composta por sedimentos proven1entes das formações componentes do Subgrupo Itaimbé. Tanto a presença da primeira fase de deformação como o preenchimento da bacia por sedimentos sin-orogênicos, satisfazem a condição de sintectonismo (Graham et al. 1986) para bacias de antepaís.

A Bacia Metassedimentar do Rio Pardo, por; i) sua localização no limite entre o Cráton do São Francisco e a Faixa Araçuáí ii) preservar evidências de um Ciclo de Wilson; e, iii) possuir unidades litoestrati-

\section{Referências}

Chaves, M.L.S.C., 1987. Conglomerados diamantíferos da região do rio Salobro (Canavieiras, Bahia). In: SBG, Simpósio sobre Sistemas Deposicionais no Pré-Cambriano, Ouro Preto, Anais, p. 155-162.

Cordani, U., 1973. Evolução geológica precambriana da faixa costeira do Brasil entre Salvador e Vitória. Inst. De Geociências, Universidade de São Paulo, São Paulo, Tese de Livre Docência, $98 \mathrm{p}$.

Cordani, U. \& lyer, S., 1976.Comentários sobre as determinações geocronológicas disponíveis na Folha Salvador.In: Pedreira, A.J. 1976. Carta Geológica do Brasil ao Milionésimo: Folha Salvador (SD.24). Brasília, MME/DNPM, 127 p. (Participacão especial de U.G. Cordani, S.S. lyer,D.A.Campos e D.R.B.Campos)

Costa Pinto, N.M.A.C., 1977.Determinaçôes isotópicas de carbono e oxigénio em rochas metassedimentares do Grupo Rio Pardo. Inst. de Geociências, Universidade Federal da Bahia, Salvador, Tese de Mestrado, 61p.

Delgado, I.M.;Pedreira, A.J.;Thorman, C.H., 1994.Geology and Mineral Resources of Brazil: A Review. International Geology Review, 36:503-544.

Dominguez, J.M.L. 1993. O emprego de estratigrafia de sequências em terrenos mesoproterozóicos do Estado da Bahia-Uma discussão: Réplica. Revista Brasileira de Geociências, 23:332-334.

Egydio-Silva, M.; Trompette, R.; Karmann, I.; Uhlein, A. 1993. A tectônica do Grupo Rio Pardo no contexto cinemático do Cráton do São Francisco. In: SBG, II Simpó sio do Cráton do São Francisco. Salvador, SBG/SGM, Anais, p. 249-251.

Einsele, G.1992.Sedimentary Basins; Evolution, Fácies and Sediment Budget.Berlin, Springer-Verlag, $628 \mathrm{p}$.

Graham, S.; Tolson, R.; Decelles, P.; Ingersoll; Baragar, E.; Caldwell, M.; Cavazza, W.; Edwards, D.; Folio, M.; Handschy, J; Lemke, L.; Moxon, L; Rice, R.; Smith, G.; White, J. 1986. Provenance modelling as a technique for analysing source terrane evolution and controls on foreland sedimentation. In: Allen, P. \& Homewood, P., (eds.), Foreland Basins. Spec. Púbis int. Ass. Sediment. 8:425-436.

Ingersoll, R.V.; Graham, S.A.; Dickinson, W.R. 1995. Remnant Ocean Basins. In: Busby, C.J. \& Ingersoll, R.V. (eds.) Tectonics of Sedimentary Basins. Cambridge, Blackwell Science, 363-391.

Karmann, L, 1987.0 Grupo Rio Pardo (Proterozóico Médio a Superior): uma cobertura paraplataformal da margem sudeste do Cráton do São Francisco. Inst. de Geociências, Universidade de São Paulo, São Paulo.iDissertacão de Mestrado, 129p.

Karmann, I.jSilva, M.E.;Trompette, R., 1989.Litoestratigrafia do Grupo Rio Pardo, Proterozóico Médio a Superior do Sudeste do Estado da Bahia. Revista Brasileira de Geociências, 19:290-302.

Mascarenhas, J.F. \& Garcia, T.W. 1989. Mapa Geocronológico do Estado da Bahia-Texto Explicativo. Salvador, SOM, 189 p. (anexo mapa na escala 1:1.000.000). 87-99. gráficas correlacionáveis com outras envolvidas na evolução da Faixa Araçuaí, constitui um terreno de alta relevância para o entendimento da evolução tectônica do Cráton do São Francisco e da Faixa Araçuaí.

Agradecimentos Este trabalho é uma contribuição ao Programa de Levantamentos Geológicos Básicos do Brasil - PLGB, executado pela CPRM -Serviço Geológico do Brasil. À Companhia Baiana de Pesquisa Mineral - CBPM pelo apoio de campo e as análises petrográficas executadas em seu laboratório, a dois revisores anónimos cujas sugestões melhoraram consideravelmente a versão preliminar do trabalho e a A. C. Pedrosa Soares pelo estímulo para sua publicação.

Mascarenhas, J.F.; Pedreira, A.J.; Gil, C.A.; Neves, J.P.; Oliveira, J.E.; Silva Filho, M.A.; Marinho, M.M. 1979. Geologia da Região Centro-Oríental da Bahia-Projeto Bahia - Bahia II - Sul da Bahia; Relatório Integrado. Brasília, MME/DNPM, 128p. (Série Geologia Básica n . 8)

Pedreira, A.J.jSouto, P.G.;Azevedo, H.C.A., 1969.Metassedimentos do Grupo Rio Pardo, Bahia-Brasil. In: SBG, Congresso Brasileiro de Geologia 23, Salvador, Anais,

Pedreira, A.J.1976.Estrutura da Bacia Metassedimentar do Rio Pardo, Bahia Brasil. In: SBG, Congresso Brasileiro de Geologia, 29, Ouro Preto, Anais, 2:157-168.

Pedreira, A.J., 1979.Bacia Metassedimentar do Rio Pardo. In: Inda, H. A. V. (org.) Geologia e Recursos Minerais do Estado da Bahia.. Salvador, SME/CPM : 1-21 (Textos Básicos, 2).

Pedreira, A.J., 1996. Geologia e Recursos Minerais da Bacia Metassedimentar do Rio PWo.Salvador, CBPM, 18 p. (Série Arquivos Abertos No. 11).

Pedrosa Soares, A.C. 1996. O Setor Setentrional da Faixa Araçuaí. In: SBG Congresso Brasileiro de Geologia, 39, Salvador, Excursão E-12:13-49.

Siqueira, L.P.;Gonçalves, J.C.;Neves, J.P., 1978.Novas considerações sobre a bacia metassedimentar do rio Pardo, Bahia. In: SBG, Congresso Brasileiro de Geologia, 30, Recife,. Anais, 1:452-466.

Souto, P.G.;Azevedo, H.C.A.;Bezerra, J.C.L., 191l.Geologia da Folha Potiraguá Nordeste. Itabuna, CEPEC/CEPLAC, 35p. (Boletim Técnico No. 15).

Souto, P.G.;Azevedo, H.C.A.jPedreira, A.J., 1912.Geologia da Folha Camacan Sudoeste. Itabuna, CEPEC/CEPLAC, 30p.(Boletim Técnico No.20).

Talwani, M. \& Heirtzler, J.R., 1964.Computation of gravity anomalies caused by two dimensional structures of arbitrary shapes. Geologic Sciences, Stanford University, 9:464-480 (Parti)

Tanner de Oliveira, M.".A. F. \& Corrêa Gomes, L.C., 1991. Ilhéus-Olivença Mafic Dyke Swarm. In: Pedreira, A.J.(ed), International Symposium on Mafic Dykes and Related Magmatism, São Paulo. Pre-Meeting Excursion: Part I-Middle to Late Proterozoic Dyke Swarms of Eastern São Francisco Cráton, p. 25-38.

Vine, S., 1998. Early Rift Zone Fácies, Early Sedimentation in Continental rifts. 